\title{
Effect of vitamin $C$ on inflammation and metabolic markers in hypertensive and/or diabetic obese adults: a randomized controlled trial
}

This article was published in the following Dove Press journal:

Drug Design, Development and Therapy

I July 2015

Number of times this article has been viewed

\author{
Mohammed S Ellulu' \\ Asmah Rahmat' \\ Ismail Patimah ${ }^{2}$ \\ Huzwah Khaza'ai ${ }^{2}$ \\ Yehia Abed ${ }^{3}$ \\ 'Department of Nutrition \\ and Dietetics, ${ }^{2}$ Department of \\ Biomedical Science, Faculty of Medicine \\ and Health Sciences, Universiti \\ Putra Malaysia, Serdang, Malaysia; \\ ${ }^{3}$ Faculty of Public Health, Al-Quds \\ University, Gaza City, Palestine
}

Background: Obesity is well associated as being an interfering factor in metabolic diseases such as hypertension and diabetes by increasing the secretion of proinflammatory markers from adipose tissue. Having healthy effects, vitamin $\mathrm{C}$ could work as an anti-inflammatory agent through its antioxidant capacity.

Registration: Registration number: FPSK_Mac [13]04.

Objective: The aim of the study reported here was to identify the effect of vitamin $\mathrm{C}$ on reducing the levels of inflammatory markers in hypertensive and/or diabetic obese adults.

Subjects and methods: Sixty-four obese patients, who were hypertensive and/or diabetic and had high levels of inflammatory markers, from primary health care centers in Gaza City, Palestine, were enrolled into one of two groups in an open-label, parallel, randomized controlled trial. A total of 33 patients were randomized into a control group and 31 patients were randomized into an experimental group. The experimental group was treated with $500 \mathrm{mg}$ vitamin $\mathrm{C}$ twice a day.

Results: In the experimental group, vitamin C significantly reduced the levels of high-sensitivity C-reactive protein (hs-CRP), interleukin 6 (IL-6), fasting blood glucose (FBG), and triglyceride (TG) after 8 weeks of treatment (overall: $P<0.001$ ); no changes appeared in total cholesterol (TC). In the control group, there were significant reductions in FBG and TG $(P=0.001$ and $P=0.026$, respectively), and no changes in hs-CRP, IL- 6 , or TC. On comparing the changes in the experimental group with those in the control group at the endpoint, vitamin $\mathrm{C}$ was found to have achieved clinical significance in treating effectiveness for reducing hs-CRP, IL-6, and FBG levels ( $P=0.01, P=0.001$, and $P<0.001$, respectively), but no significant changes in TC or TG were found.

Conclusion: Vitamin C (500 mg twice daily) has potential effects in alleviating inflammatory status by reducing hs-CRP, IL-6, and FBG in hypertensive and/or diabetic obese patients.

Keywords: obesity, hypertension, diabetes, anti-inflammatory, adiposity, Vitamin C

\section{Introduction}

Vitamin $\mathrm{C}$ is a water-soluble reducing agent and antioxidant due to its characteristic of donating an electron, and all of its metabolic roles are probably due to this function. It acts as an electron donor for eight human enzymes and neutralizes free radicals to protect from damage. ${ }^{1}$ Because of its structural similarity to glucose, it can replace glucose in many chemical reactions, and it can prevent the non-enzymatic glycosylation of proteins. ${ }^{2}$ A possible mechanism for the beneficial effect of plasma vitamin $\mathrm{C}$ on heart failure may relate to the fact that it enhances arterial dilation through its effect on nitric-oxide release, ${ }^{3}$ as it protects tissues from oxidative stress and thus plays an important role in preventing diseases. ${ }^{1}$ Large epidemiological studies have reported
Correspondence: Asmah Rahmat Department of Nutrition and Dietetics, Faculty of Medicine and Health Sciences, Universiti Putra Malaysia, 43400 Serdang, Selangor, Malaysia

Tel +60 173972310

Email asmah@upm.edu.my 
that dietary intake of antioxidants inversely correlates with hypertension. ${ }^{4,5}$ Particularly, treatment with ascorbic acid has been reported to significantly improve systolic blood pressure and diastolic blood pressure in mild-to-moderately hypertensive patients. ${ }^{6}$ Vitamin $\mathrm{C}$ can also protect against consequences of diabetes mellitus (DM) like diabetic retinopathy, ${ }^{7}$ improve high-density lipoprotein-cholesterol (HDL-c), ${ }^{8,9}$ and improve endothelial function. ${ }^{10}$

Adiposity is defined as an accumulation of body fat that predisposes to metabolic syndrome. The hypothesized physiological mechanism is the state of chronic low-grade inflammation that is associated with excess adipose tissue. It may explain the development of obesity-related pathologies, such as type-2 DM and cardiovascular disease. ${ }^{11}$ Further, obesity plays an important role in the development of insulin resistance that triggers the associated comorbidities of metabolic syndrome, such as atherosclerosis, dyslipidemia, hypertension, prothrombotic state, and hyperglycemia. ${ }^{12}$ The link between obesity and inflammation has been derived from the finding that the proinflammatory cytokines tumor necrosis factor-alpha (TNF- $\alpha$ ) and interleukin 6 (IL-6) are overexpressed in obesity. ${ }^{13}$ A high level of cytokines generally, and IL-6 particularly, is associated with decreased nitric oxide and increased reactive oxygen species, which lead to endothelial and microvascular dysfunction. ${ }^{14}$ Accordingly, increased serum level of IL-6 stimulates the liver to synthesize and secrete the low-grade systemic inflammatory marker C-reactive protein (CRP). ${ }^{15}$

Through the production of reactive oxygen species, the inflammatory process may deplete stores of antioxidants, including vitamin $\mathrm{C} ;{ }^{16}$ so, its usage in treating inflammation associated with diseases has been considered. It is used with cancers, ${ }^{17,18}$ gastritis, ${ }^{19}$ lung diseases, and asthma. ${ }^{20}$ However, Jialal and Singh ${ }^{21}$ asked whether vitamin $\mathrm{C}$ acts as an anti-inflammatory agent. They discussed studies relating vitamin $\mathrm{C}$ with $\mathrm{CRP}$ through cross-sectional assessment rather than clinical trials.

The objective of the study reported here was to evaluate the effect of vitamin $\mathrm{C}$ on inflammatory markers (serum level of IL-6 and CRP) in hypertensive and/or diabetic obese adults. We also aimed to find out the change in metabolic markers - fasting blood glucose (FBG) and lipid-profile factors, total cholesterol (TC), and triglyceride (TG) after 8 weeks of vitamin $\mathrm{C}$ intervention.

\section{Subjects and methods Study population}

Eligible participants were obese (body mass index $[\mathrm{BMI}] \geq 30 \mathrm{~kg} / \mathrm{m}^{2}$ ), hypertensive, and/or diabetic patients between 20 and 60 years of age who systemically visited primary health care centers for follow-up at three locations in Gaza City, Palestine. The diagnosis and selection of hypertensive and diabetic cases depended on patients' selfreporting and this was then proven by patients' medical history records obtained from the health care center. All of the diabetic patients had type-2 DM. Participants were eligible if they had a high CRP level (high-sensitivity C-reactive protein $[\mathrm{hs}-\mathrm{CRP}] \geq 6 \mathrm{mg} / \mathrm{L}$ ). Patients were excluded if they had any acute illness within the past 2 weeks, regularly used nonsteroidal anti-inflammatory drugs (naproxen and cyclooxygenase-2 inhibitors) and/or cholesterol-lowering agents (statins), suffered from systemic and inflammatory diseases that change physical or laboratory tests (arthritis, renal, thyroid, hepatic, respiratory, gout, active malignant disease, pregnancy, breastfeeding), and/or documented intolerability to vitamin $\mathrm{C}$.

\section{Study design and intervention}

The clinical trial was randomized, open-label, controlled, and parallel, and performed in compliance with the $W M A$ [World Medical Association] Declaration of Helsinki: Ethical Principles for Medical Research Involving Human Subjects adopted by the 18th WMA General Assembly, Helsinki, Finland, June 1964, and amended by 59th WMA General Assembly, Seoul, Korea, October 2008 (number: PHRC/HC/11/13, March 4, 2013). The trial was approved by the Ethics Committee of Universiti Putra Malaysia (June 21, 2013). It was conducted at the Ministry of Health primary health-care centers in Gaza City, Palestine, and followed the Good Clinical Practice guidelines of the Department of Clinical Research, Faculty of Public Health, Al-Quds University.

Recruited patients were randomly assigned to a vitamin $C$ treatment (experimental) group or control group using manual-blocks formation based on the rolling of a die. Patients in the experimental group were assigned to treatment with $1 \mathrm{~g}$ vitamin $\mathrm{C}$ per day (500 mg twice per day), while the control group was kept free of supplements. The vitamin $\mathrm{C}$ was supplied in tablets (C-Tamin-500 Tablets; Rekah Pharmaceutical Industry Ltd, Holon, Israel) containing $500 \mathrm{mg}$ vitamin $\mathrm{C}$. The decision to use $1 \mathrm{~g}$ of vitamin $\mathrm{C}$ daily was made based on the previous study of Block et al. ${ }^{22}$ In that study, they used $515 \mathrm{mg}$ of vitamin $\mathrm{C}$ for 8 weeks, the obtained variance between means (after treatment-baseline) of hs-CRP was $0.5 \mathrm{mg} / \mathrm{L}$. In the present study, additional double variance was needed to range between 0.9 and $1.0 \mathrm{mg} / \mathrm{L}$, which required a double dose of vitamin $\mathrm{C}$.

Participants in both groups were advised to maintain constant daily lifestyle habits unless they progressed to any 
of the excluding criteria. Based on an adapted form of Global Physical Activity Questionnaire (v 2), ${ }^{23}$ the majority of participants indicated they undertook a low level of physical activity (PA), while the remaining participants indicated they undertook a moderate level of PA. None of the participants said they undertook a high level of PA before or during the trial. The participants were distributed in approximate equality in terms of smoking habit, which was evaluated by an adapted and modified form of the Behavioral Risk Factor Surveillance System. ${ }^{24}$ In terms of smoking status, each patient was categorized as a current smoker, past smoker, passive smoker, or nonsmoker.

The intervention continued for 8 weeks, and the participants returned for follow-up visits every 2 weeks. At study baseline (randomization time), we performed anthropometric measurements (BMI, waist circumference [WC], and blood pressure [systolic and diastolic]) and blood sampling. We measured systemic inflammatory markers (hs-CRP and IL-6) and metabolic markers (FBG, TC, and TG).

Sample size was estimated as 32 per a group to detect a reduction in inflammatory and metabolic markers at a $P$-value 0.05 with a power of $90 \%$, and a dropout rate of $10 \%$ was expected. Thus, we aimed to recruit 72 patients.

\section{Tools}

A Seca Stadiometer used to assess BMI according to the World Health Organization (WHO) classification ${ }^{25}$ (underweight: $<18.5 \mathrm{~kg} / \mathrm{m}^{2}$; normal weight: $18.5 \leq 25.0 \mathrm{~kg} / \mathrm{m}^{2}$; overweight: $25.0 \leq 30.0 \mathrm{~kg} / \mathrm{m}^{2}$; obese: $\geq 30 \mathrm{~kg} / \mathrm{m}^{2}$ ), and a Seca 201 nonelastic tape was used to determine WC according to the National Institute for Health and Clinical Excellence classification $^{26}$ (male: normal $<102 \mathrm{~cm}$, high $\geq 102 \mathrm{~cm}$; female: normal $<88 \mathrm{~cm}$, high $\geq 88 \mathrm{~cm}$ ).

Quantitative method was used to assess FBG, TC, TG, and hs-CRP. A CRP turbidimetric latex 1:5 kit used to assess hs-CRP, an enzymatic colorimetric method with glucose oxidase was used to estimate FBG, and commercial kits were used to assess TC and TG. All quantitative data were evaluated using a Mindray BS-120 Chemistry Analyzer. IL-6 was assessed using enzyme-linked immunosorbent assay kits (Sigma-Aldrich Co) via One-Run reading.

Blood was collected by a trained nurse or physician of the health center. A $7 \mathrm{~mL}$ blood sample was drawn into a polyethylene evacuated tube then divided into two separate tubes. One of the tubes of blood was used to evaluate quantitative biochemical measures (hs-CRP, FBG, TC, and $\mathrm{TG}$ ), and the other was stored at $-80^{\circ} \mathrm{C}$, after separation of serum, for analysis through one-run of an enzyme-linked immunosorbent assay reader to assess IL-6.
All participants completed an informed consent form before attending the study sessions and blood-sample collection. All participants were assured of confidentiality and any required information was provided to them. It was clearly explained to them that participation would be voluntary and they could decline to participate at any time. A case-report form for each patient was used for data handling and record keeping.

Every attempt was made to minimize biases and to conduct the study in the most ethical manner possible.

\section{Withdrawal and monitoring criteria}

We established withdrawal criteria to manage the response and dropout of participants. Patient follow-ups were discontinued if: the participant withdrew consent or become noncooperative; the participant developed an illness or condition that changed physical or laboratory tests, as explained earlier in the exclusion criteria; the study supplements resulted in the development of intolerable adverse effects; the participant vomited the supplement within 4 hours of administration; and/or a female participant became pregnant.

Additionally, the monitoring criteria were used to evaluate patients' involvement and compliance. The number of supplement pills taken every 2 weeks was recorded, participants were required to keep a diary and their entries were monitored, and participants received a phone call daily reminding them of the dose time.

\section{Statistical analysis}

Data were analyzed using SPSS software (v 21.0; IBM Corporation, Armonk, NY, USA). Descriptive statistics, including $\chi^{2}$, were used to compare the categorical variables of subjects' characteristics in both groups. After the assumption of normality, continuous variables were presented as mean \pm standard deviation. Independent $t$-tests were used to assess the difference between the groups at the baseline of randomization and end points of study. Paired $t$-tests were used to evaluate the difference within the groups. A $P$-value of $\leq 0.05$ was considered statistically significant and the level of confidence was $95 \%$ at a power equal to $90 \%$.

\section{Results}

\section{Study population and intervention}

The trial aimed to evaluate the effect of vitamin $C$ on inflammatory (hs-CRP, IL-6) and metabolic markers (FBG, TC, and TG) in hypertensive and/or diabetic obese patients. The recruitment of study participants began in November 2013 and was completed in May 2014. Of 484 screened patients, 108 were enrolled in the study and assigned randomly to one of 
three groups: control or one of two experimental/intervention groups: vitamin $\mathrm{C}$ treatment and long-chain omega-3 polyunsaturated fatty acid treatment.

This paper reports on two groups, the control and vitamin C treatment groups. The progression of patients through the study is shown in Figure 1. Sixty-four patients completed the study (31 patients in the intervention group and 33 in the control group). Eight patients were lost during follow-up because they met one or more of the withdrawal criteria (five patients in the intervention group and three in the control group).

\section{Balance at baseline}

The baseline demographic (age, sex, smoking, level of PA, and health status/disease), anthropometric (BMI and WC), and clinical characteristics (hs-CRP, IL-6, FBG, TC, and TG) of the patients in both groups were comparable (Table 1). A total of 72 patients were recruited at the baseline to participate in the study. To assess the balance between the groups, comparisons of all patients' characteristics were undertaken.

No statistically significant difference for any variable of comparison was detected; no difference appeared between the groups in terms of age, sex, smoking habit, level of PA, or health status/disease. In addition, equality between the groups was assumed in terms of the anthropometric measurement of BMI and WC for males and females. Further, no significant differences were found when comparing the groups in terms of the clinical variables hs-CRP, IL-6, FBG, TC, and TG. These results for all variables indicate balance at baseline between the groups and indicate equality, because the differences did not reach the significance level of a $P$-value $\leq 0.05$.

\section{Changes in clinical characteristics after 8 weeks}

Table 2 presents the changes in patients' clinical characteristics after 8 weeks, between the end point (after treatment) and

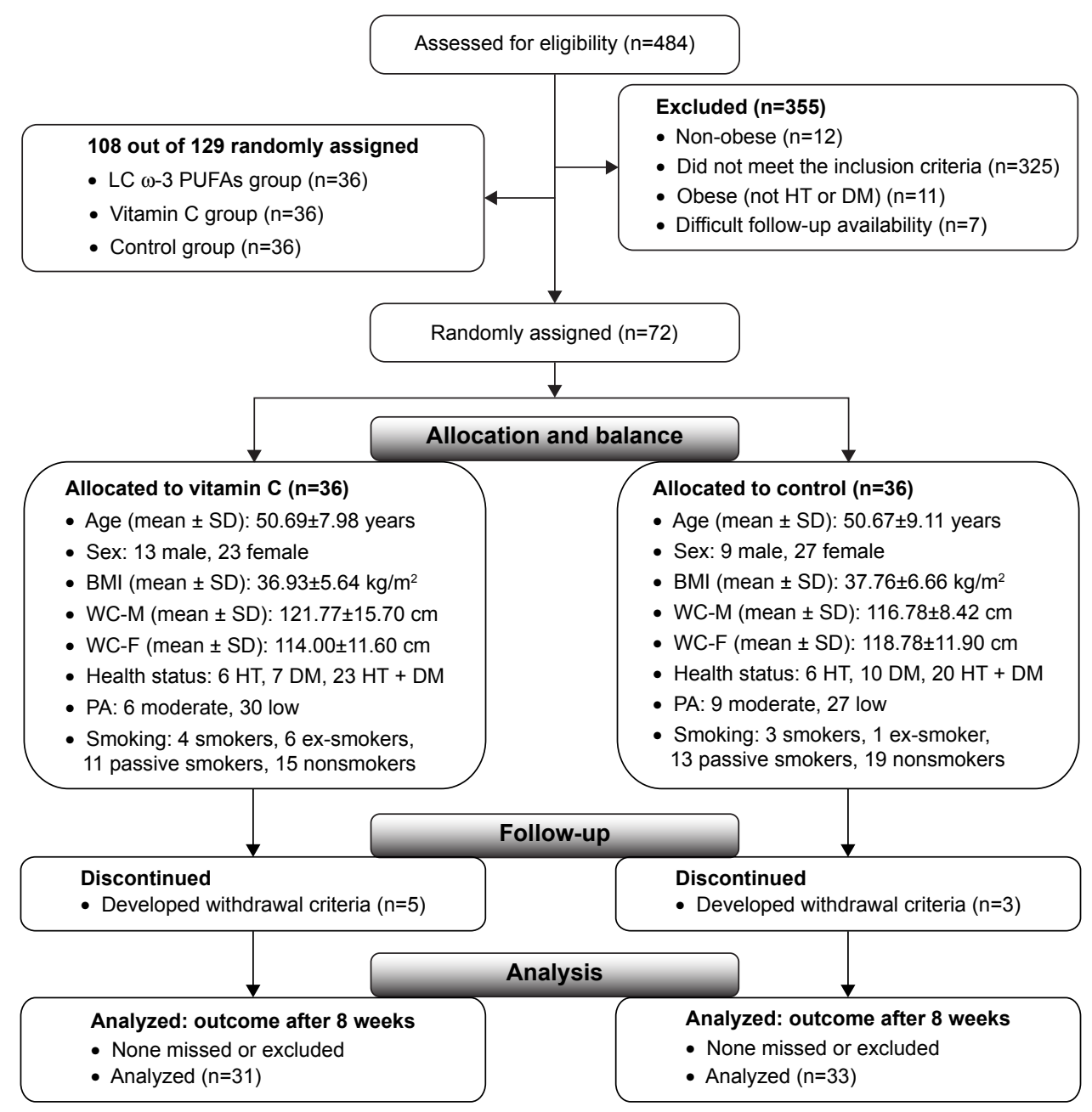

Figure I Consolidated Standards of Reporting Trials (CONSORT) flowchart.

Abbreviations: BMI, body mass index; DM, diabetes mellitus; HT, hypertension; LC $\omega-3$ PUFAs, long-chain omega-3 polyunsaturated fatty acids; PA, level of physical activity; SD, standard deviation; WC-F, waist circumference - females; WC-M, waist circumference - males. 
Table I Demographic, anthropometric, and clinical variables at baseline (randomization) in both groups

\begin{tabular}{|c|c|c|c|c|}
\hline Variable & $\begin{array}{l}\text { Vitamin C group } \\
(n=36)\end{array}$ & $\begin{array}{l}\text { Control group } \\
(n=36)\end{array}$ & Test value & $P$-value \\
\hline \multicolumn{5}{|l|}{ Demographic and lifestyle } \\
\hline Age (years) (mean $\pm S D)$ & $50.69 \pm 7.98$ & $50.67 \pm 9.11$ & $t=0.014^{\mathrm{a}}$ & 0.989 \\
\hline Sex (male, female) & 13,23 & 9,27 & $\chi^{2}=1.047^{b}$ & 0.443 \\
\hline Smoking (S, ES, PS, NS) & $4,6,11,15$ & $3,1,13,19$ & $\chi^{2}=4.352^{b}$ & 0.226 \\
\hline PA (moderate, low) & 6,30 & 9,27 & $\chi^{2}=0.758^{b}$ & 0.563 \\
\hline Disease (HT, DM, HT + DM) & $6,7,23$ & $6,10,20$ & $\chi^{2}=0.739^{b}$ & 0.691 \\
\hline \multicolumn{5}{|l|}{ Anthropometric } \\
\hline BMI $\left(\mathrm{kg} / \mathrm{m}^{2}\right)($ mean $\pm \mathrm{SD})$ & $36.93 \pm 5.64$ & $37.76 \pm 6.66$ & $t=-0.573^{\mathrm{a}}$ & 0.569 \\
\hline WC-M $(\mathrm{cm})($ mean $\pm \mathrm{SD})$ & $121.77 \pm 15.70$ & $116.78 \pm 8.42$ & $t=0.96 \mathrm{I}^{\mathrm{a}}$ & 0.349 \\
\hline WC-F $(\mathrm{cm})($ mean $\pm S D)$ & $1 \mid 4.00 \pm 11.60$ & $118.78 \pm 11.90$ & $t=-1.423^{\mathrm{a}}$ & 0.161 \\
\hline \multicolumn{5}{|l|}{ Clinical } \\
\hline hs-CRP (mg/L) (mean \pm SD) & $14.36 \pm 8.69$ & $14.02 \pm 13.70$ & $t=0.125^{\mathrm{a}}$ & 0.901 \\
\hline IL-6 (pg/mL) (mean \pm SD) & $2.14 \pm 0.78$ & $1.97 \pm 0.72$ & $t=0.965^{\mathrm{a}}$ & 0.338 \\
\hline $\mathrm{FBG}(\mathrm{mg} / \mathrm{dL})($ mean $\pm \mathrm{SD})$ & $189.42 \pm 80.60$ & $187.83 \pm 65.92$ & $t=0.091^{\mathrm{a}}$ & 0.928 \\
\hline $\mathrm{TC}(\mathrm{mg} / \mathrm{dL})($ mean $\pm \mathrm{SD})$ & $204.58 \pm 34.78$ & $208.72 \pm 38.27$ & $t=-0.480^{\mathrm{a}}$ & 0.633 \\
\hline TG $(\mathrm{mg} / \mathrm{dL})($ mean $\pm \mathrm{SD})$ & $225.44 \pm 94.72$ & $200.42 \pm 102.70$ & $t=1.074^{\mathrm{a}}$ & 0.286 \\
\hline
\end{tabular}

Notes: Normal ranges of clinical characteristics according to the American Heart Association and Center for Disease Control and Prevention (AHA/CDC): hs-CRP $<3.0 \mathrm{mg} / \mathrm{L}$, IL-6 $<1.0 \mathrm{pg} / \mathrm{mL}$, and according to National Cholesterol Education Program and Adult Treatment Panel-III: FBG $<\mathrm{II} 0 \mathrm{mg} / \mathrm{dL}, \mathrm{TC}<200 \mathrm{mg} / \mathrm{dL}, \mathrm{TG}<\mathrm{I} 50 \mathrm{mg} / \mathrm{dL}$. ${ }^{a}$ Independent-samples $t$-test. ${ }^{b} \mathrm{Chi}$-square test.

Abbreviations: S, smoker; ES, ex-smoker; PS, passive smoker; NS, non-smoker; BMI, body mass index; DM, diabetes mellitus; FBG, fasting blood glucose; hs-CRP, highsensitivity C-reactive protein; HT, hypertension; IL-6, interleukin 6; PA, level of physical activity; SD, standard deviation; TC, total cholesterol; TG, triglyceride; WC-F, waist circumference - females; WC-M, waist circumference - males.

baseline (before treatment), for both groups. In the vitamin C group, the changes appear in four variables after 8 weeks of intervention: hs-CRP, IL-6, FBG, and TG can be seen to have reduced significantly (overall, $P<0.001$ ). In the control group, the change appears in two variables after 8 weeks without added supplements: FBG $(P=0.001)$ and TG $(P=0.026)$. Due to the open-label nature of the study, the changes within the control group could be attributed to changes in lifestyle factors, such as eating habit or level of PA.

At the end of the study, after 8 weeks of treatment, in the vitamin $\mathrm{C}$ group, there were 31 valid patients and five patients who discontinued. In the control group, there were 33 valid patients and three patients who discontinued. The overall response rate was $88.88 \% ; 86.11 \%$ in the vitamin C group and $91.66 \%$ in the control group.

However, the statistically significant changes found within the treatment group before and after the treatment period did not necessarily mean the supplement was effective in reducing the risk of high levels of patients' clinical characteristics. To determine this, we compared the differences between the groups at the end point (after treatment) to determine the clinical significance of vitamin C. Significance was detected for three of the clinical variables: hs-CRP, IL-6, and FBG ( $P=0.01, P=0.001$, and $P<0.001$, respectively), while it was absent for TC and TG. This means that the reduction in levels of clinical variables after 8 weeks of daily use of $1 \mathrm{~g}$ of vitamin $\mathrm{C}$ were true and resulted from the effect of the supplement.

\section{Discussion}

The literature indicates that the anti-inflammatory properties and antioxidant capacity of vitamin $\mathrm{C}$ can be attributed to their ability to modulate the DNA binding activity of nuclear factor-kappa $\mathrm{B} \cdot{ }^{27,28}$ The activation is primarily promoted by

Table 2 The change in clinical characteristics after 8 weeks of intervention in both groups

\begin{tabular}{|c|c|c|c|c|c|}
\hline \multirow[t]{2}{*}{ Characteristic } & \multicolumn{2}{|c|}{ Vitamin C $(n=3 I)($ mean $\pm S D)$} & \multicolumn{2}{|c|}{ Control $(n=33)($ mean $\pm S D)$} & \multirow[t]{2}{*}{$P$-value } \\
\hline & Before & After & Before & After & \\
\hline hs-CRP (mg/L) & $14.86 \pm 9.20$ & $7.74 \pm 4.53 *$ & $14.50 \pm 14.26$ & $11.81 \pm 7.33$ & $0.01 * *$ \\
\hline IL-6 (pg/mL) & $2.20 \pm 0.75$ & $1.40 \pm 0.53 *$ & $1.95 \pm 0.75$ & $2.01 \pm 0.87$ & $0.001 * *$ \\
\hline FBG (mg/dL) & $188.13 \pm 81.24$ & $126.16 \pm 34.06 *$ & $187.15 \pm 64.89$ & $161.91 \pm 37.97 *$ & $<0.001 * *$ \\
\hline $\mathrm{TC}(\mathrm{mg} / \mathrm{dL})$ & $207.7 I \pm 36.20$ & $196.48 \pm 33.89$ & $211.03 \pm 39.04$ & $213.38 \pm 38.77$ & 0.071 \\
\hline TG (mg/dL) & $223.81 \pm 87.88$ & $155.10 \pm 48.12^{*}$ & $202.91 \pm 107.00$ & $183.45 \pm 95.82 *$ & 0.138 \\
\hline
\end{tabular}

Notes: *Change was significant at the 0.05 level (two-tailed) (calculated by paired-samples $t$-test). **Difference was significant at the 0.05 level (two-tailed) (calculated by independent-samples $t$-test).

Abbreviations: FBG, fasting blood glucose; hs-CRP, high-sensitivity C-reactive protein; IL-6, interleukin 6; SD, standard deviation; TC, total cholesterol; TG, triglyceride. 
oxidative stress and leads to cytokine-induced expression of cell adhesion molecules in the vascular endothelium, and to the TNF- $\alpha$ - and IL-6-induced production of CRP by the liver. ${ }^{29}$ Jang et $\mathrm{al}^{30}$ identified that vitamin $\mathrm{C}$ can reduce the plasma levels of the inflammatory mediators TNF- $\alpha$ and IL-6 via downregulation of hepatic mRNA expression.

\section{Effect on hs-CRP and IL-6}

In the present study, the effect of $1 \mathrm{~g}$ vitamin $\mathrm{C}$ on the inflammatory markers hs-CRP and IL-6 was evaluated after 8 weeks of daily intake. In the experimental group, significant reductions in hs-CRP and IL-6 levels were observed, and repeated tests between the experimental and control groups identified the clinical effectiveness of the intervention factor vitamin $\mathrm{C}$ in alleviating inflammation. The fact that treating the inflammatory status can be attributed to the effect of vitamin $\mathrm{C}$ is discussed following with reference to previous studies involving healthy and diseased populations.

Similar evidence is available to support the present results. Peluso et $\mathrm{al}^{31}$ found that mixed fruit-juice drink rich in vitamin $\mathrm{C}$ has the ability to reduce postprandial stress, mediated through IL-6 and TNF- $\alpha$, in healthy overweight participants. Also, Jang et $\mathrm{al}^{30}$ proved that feeding animals a vitamin $\mathrm{C}$ rich diet could improve proinflammatory cytokine levels, including IL-6 and TNF- $\alpha$. In the same context, consistent results were observed by Zhang et $\mathrm{al}^{32}$ who found that inflammatory status appeared with plasma vitamin $\mathrm{C}$ deficiency. Zhang et al's study aimed to find out the effect of vitamin C supplementation on inflammatory status in maintenance hemodialysis patients with low vitamin C level and high hs-CRP level. The study was conducted in two groups; in the first, patients were given $200 \mathrm{mg}$ per day vitamin C for 3 months, then the vitamin $C$ supplementation was withdrawn for the next 3 months. In the second group, patients were not given vitamin $\mathrm{C}$ in the first 3 months, then were orally administered with $200 \mathrm{mg}$ vitamin $\mathrm{C}$ per day for the next 3 months.

Further, Mikirova et a ${ }^{17}$ summarized data of potentially therapeutic plasma ascorbate concentrations. Intravenous vitamin $\mathrm{C}$ can improve cancer outcome via modulated inflammation by reducing CRP. Block et al ${ }^{33}$ also investigated whether vitamins $\mathrm{C}$ or $\mathrm{E}$ could reduce CRP in healthy nonsmoker participants. Three groups were randomized into one of three groups: $1,000 \mathrm{mg}$ per day vitamin $\mathrm{C}, 800$ IU per day vitamin $\mathrm{E}$, or placebo for 2 months. Among the participants with CRP indicative of elevated cardiovascular risk ( $\geq 1 \mathrm{mg} / \mathrm{L}$ ), vitamin $\mathrm{C}$ was found to reduce median CRP by $25.3 \%$ vs placebo $(P=0.02)$. Similarly, Block et $\mathrm{al}^{22}$ determined the effect of vitamin $\mathrm{C}$ in reducing plasma $\mathrm{CRP}$ in active and passive smokers. Participants in that study were randomized to receive placebo or vitamin C (515 mg/day), adjusted by BMI. The supplementation of vitamin $\mathrm{C}$ yielded a $24.0 \%$ reduction $(95 \%$ confidence interval -38.9 to -5.5 , $P=0.036$ compared with control) in plasma CRP.

In cross-sectional studies by Wannamethee et $\mathrm{al}^{34}$ evaluating the relationship between inflammatory markers and blood levels of vitamin C, the plasma level of vitamin C was found to be associated with a significant reduction in risk of heart failure in men with and without pre-existing myocardial infarction. The inverse association between plasma vitamin $\mathrm{C}$ and heart failure in men was explained by traditional risk factors involving reduction of CRP. Similarly, Wannamethee et $\mathrm{al}^{35}$ examined the cross-sectional associations between dietary and plasma vitamin C, and CRP for subjects free of DM or heart disease. Dietary and plasma vitamin $\mathrm{C}$ were significant inversely correlated with CRP ( $r=-0.10$ and $r=-0.16$, respectively; $P<0.001)$. Moreover, Ford et al ${ }^{16}$ examined the cross-sectional relationship between CRP and vitamin $\mathrm{C}$ level, and found that CRP was significantly inversely associated with vitamin $\mathrm{C}$.

Conversely, results different and inconsistent with the results of the present study were found by Aguiló et $\mathrm{al}^{36}$ and Khajehnasiri et al. ${ }^{37}$ Aguiló et al $^{36}$ found $500 \mathrm{mg}$ per day of vitamin C did not reduce the level of IL-6 induced by exercise after 15 days of supplementation. Similarly, Khajehnasiri et $\mathrm{al}^{37}$ undertook a randomized, double-blind, placebocontrolled, parallel trial to identify the role of vitamin $\mathrm{C}$ (250 mg twice a day) and/or omega-3 fatty acids (180 mg of eicosapentaenoic acid and $120 \mathrm{mg}$ docosahexaenoic acid) in inflammatory markers among 136 shift workers with a depression score $\geq 10$ in 21-item Beck Depression Rating Scale for 60 days. Omega-3 plus vitamin $C$ was associated with a decrease in depression score $(P<0.05)$, and supplementation of omega-3 fatty acids without vitamin $\mathrm{C}$ was associated with a reduction in depression score $(P<0.0001)$ and hs-CRP concentration $(P<0.01)$, but no effect was observed for vitamin $\mathrm{C}$ alone.

\section{Effect on FBG}

In the present study, the effect of vitamin $\mathrm{C}$ on FBG was examined after 8 weeks of daily intake. It was found to have reduced significantly in both the experimental and control groups. In repeated tests between the experimental and control groups at the end point to identify the efficacy of vitamin $C$, clinical significance was achieved. The fact that treating the elevated level of FBG can be attributed to the effect of vitamin $\mathrm{C}$ can be observed from previous studies. For instance, Afkhami-Ardekani and Shojaoddiny-Ardekani ${ }^{38}$ found $1 \mathrm{~g}$ of vitamin $\mathrm{C}$ effectively reduced FBG and glycated 
hemoglobin $\left(\mathrm{HbA}_{1 \mathrm{c}}\right)$ in patients with type-2 DM, and Sargeant et $\mathrm{al}^{39}$ examined the cross-sectional association between plasma vitamin $\mathrm{C}$ and $\mathrm{HbA}_{1 \mathrm{c}}$ in self-reported $\mathrm{DM}$, finding that the mean plasma vitamin $\mathrm{C}$ level was significantly higher in individuals with $\mathrm{HbA}_{1 \mathrm{c}}$ levels $<7 \%$.

However, different results were obtained by Siavash and Amini ${ }^{8}$ who enrolled 50 patients with type-2 DM into three groups. The first group received $1 \mathrm{~g}$ vitamin $\mathrm{C}$, the second received $600 \mathrm{mg}$ gemfibrozil, and the third received a combination of both. The study aimed to find out the differences in lipid profile and blood glucose due to the interventions. The results indicate that vitamin $\mathrm{C}$ had similar effects to gemfibrozil on HDL-c but no effects on other lipid biomarkers or FBG. Similarly, Dakhale et $\mathrm{al}^{40}$ examined the effect of oral vitamin $\mathrm{C}$ with or without metformin on $\mathrm{FBG}, \mathrm{HbA}_{1 \mathrm{c}}$, and plasma ascorbic acid levels in type-2 DM patients in a randomized controlled trial lasting 12 weeks. Oral supplementation of vitamin $\mathrm{C}$ with metformin was found to reverse ascorbic acid levels in blood, reduce $\mathrm{FBG}$, and improve $\mathrm{HbA}_{1 \mathrm{c}}$, while there was no meaningful result for vitamin $\mathrm{C}$ alone.

\section{Effect on TC and TG}

The present study examined the effect of vitamin $\mathrm{C}$ on $\mathrm{TC}$ and TG after 8 weeks of daily intake. In both the experimental and control groups, the level of TC was not affected by the intervention. In contrast, TG was found to be significantly reduced in both the experimental and control groups after 8 weeks. In repeated tests between the experimental and control group at the end point to identify the efficacy of vitamin $\mathrm{C}$, the effect of vitamin $\mathrm{C}$ on both TC and TG did not reach clinical significance. Similar results have been observed for the effect of vitamin $\mathrm{C}$ on TC and TG. For example, Afkhami-Ardekani and Shojaoddiny-Ardekani ${ }^{38}$ found $1 \mathrm{~g}$ of vitamin $\mathrm{C}$ could effectively reduce $\mathrm{TG}$ level in type-2 DM patients but not the TC level. Likewise, Siavash and $\mathrm{Amini}^{8}$ found no valuable effects of vitamin $\mathrm{C}$ on any lipid biomarker except HDL-c.

Finally, in contrast, Peluso et $\mathrm{al}^{31}$ documented that the ingestion of a high fat meal with a fruit juice drink rich in vitamin $\mathrm{C}$ could significantly reduce plasma levels of TC and TG, and Gaur and Dixit ${ }^{9}$ found that $\mathrm{TC}$ was reduced by vitamin $\mathrm{C}$ intervention.

\section{Conclusion}

At baseline of the randomization process, we proved the balance between the groups to be approximate equality in terms of patient demographics and clinical variables. None of the patients' characteristics violated this, so equality was assumed in all aspects. The strength of our study lies in the comparison between the experimental and control groups at the end point of the study. As far as we are aware, no previous studies have been interested in evaluating comparisons of the clinical efficacy of vitamin $\mathrm{C}$, while the majority have been interested in within-group before and after tests only. Our results indicate a clear effect of $1 \mathrm{~g}$ of vitamin $\mathrm{C}$ in alleviating inflammatory markers (hs-CRP and IL-6) among hypertensive and/or diabetic obese adults. Also, vitamin $\mathrm{C}$ strongly affected the level of FBG, significantly reducing it after 8 weeks of daily intake. For the lipid-profile variables TC and TG, our results are consistent with those of AfkhamiArdekani and Shojaoddiny-Ardekani ${ }^{38}$ who found a positive effect of vitamin $\mathrm{C}$ on TG but no effect on TC.

We found that a moderate amount of vitamin $\mathrm{C}$ can significantly treat and reduce the inflammation, as measured by hs-CRP and IL-6, in hypertensive and/or diabetic adults and also helps to reduce FBG levels. Additional studies of different durations are needed to further explore the role of vitamin $\mathrm{C}$ in the lipid profile.

\section{Acknowledgments}

The authors extend sincere thanks to the patients for their willingness to participate in this study. Publication cost of this research is covered by Faculty of Medicine and Health Sciences, Universiti Putra Malaysia (UPM).

\section{Disclosure}

The authors declare that they do not have anything to disclose regarding funding or conflicts of interest with respect to this work.

\section{References}

1. Wilson JX. Regulation of vitamin C transport. Annu Rev Nutr. 2005;25: 105-125.

2. Afkhami-Ardekani M, Vahidi AR, Borjian L, Borjian L. Effect of vitamin $\mathrm{C}$ supplement on glycosylated hemoglobin in patients with type 2 diabetes. J Shah Sad Univ. 2003;10:15-18.

3. Plantinga Y, Ghiadoni L, Magagna A, et al. Supplementation with vitamins $\mathrm{C}$ and $\mathrm{E}$ improves arterial stiffness and endothelial function in essential hypertensive patients. Am J Hypertens. 2007;20(4):392-397.

4. Salonen RM, Nyyssönen K, Kaikkonen J, et al; Antioxidant Supplementation in Atherosclerosis Prevention Study. Six-year effect of combined vitamin $\mathrm{C}$ and $\mathrm{E}$ supplementation on atherosclerotic progression: the Antioxidant Supplementation in Atherosclerosis Prevention (ASAP) Study Circulation. 2003;107(7):947-953.

5. Myint PK, Luben RN, Welch AA, Bingham SA, Wareham NJ, Khaw KT Plasma vitamin $\mathrm{C}$ concentrations predict risk of incident stroke over $10 \mathrm{y}$ in 20649 participants of the European Prospective Investigation into Cancer Norfolk prospective population study. Am J Clin Nutr. 2008; 87(1):64-69.

6. Duffy SJ, Gokce N, Holbrook M, et al. Treatment of hypertension with ascorbic acid. Lancet. 1999;354(9195):2048-2049.

7. Jariyapongskul A, Rungjaroen T, Kasetsuwan N, Patumraj S, Seki J, Niimi H. Long-term effects of oral vitamin C supplementation on the endothelial dysfunction in the iris microvessels of diabetic rats. Microvasc Res. 2007;74(1):32-38. 
8. Siavash M, Amini M. Vitamin C may have similar beneficial effects to Gemfibrozil on serum high-density lipoprotein-cholesterol in type 2 diabetic patients. J Res Pharm Pract. 2014;3(3):77-82.

9. Gaur GS, Dixit AK. Comparative study of vitamin C on serum lipid profile in healthy male and female human subjects. J Sci Res. 2012; 4(3): $775-781$.

10. Montero D, Walther G, Stehouwer A, Houben A, Beckman J, Vinet A. Effect of antioxidant vitamin supplementation on endothelial function in type 2 diabetes mellitus: a systematic review and meta-analysis of randomized controlled trials. Obes Rev. 2014;15(2):107-116.

11. Medzhitov R. Origin and physiological roles of inflammation. Nature. 2008;454(7203):428-435.

12. Boura-Halfon S, Zick Y. Phosphorylation of IRS proteins, insulin action, and insulin resistance. Am J Physiol. 2009;296(4): E581-E591.

13. Hotamisligil GS, Shargill NS, Spiegelman BM. Adipose expression of tumor necrosis factor-alpha: direct role in obesity-linked insulin resistance. Science. 1993;259(5091):87-91.

14. Emanuela F, Grazia M, Marco de R, Maria Paola L, Giorgio F, Marco B. Inflammation as a Link between Obesity and Metabolic Syndrome. J Nutr Metab. 2012;2012:476380.

15. Zhang S, Liu Q, Wang J, Harnish DC. Suppression of interleukin6-induced C-reactive protein expression by FXR agonists. Biochem Biophys Res Commun. 2009;379(2):476-479.

16. Ford ES, Liu S, Mannino DM, Giles WH, Smith SJ. C-reactive protein concentration and concentrations of blood vitamins, carotenoids, and selenium among United States adults. Eur J Clin Nutr. 2003;57(9):1157-1163.

17. Mikirova N, Casciari J, Riordan N, Hunninghake R. Clinical experience with intravenous administration of ascorbic acid: achievable levels in blood for different states of inflammation and disease in cancer patients. J Transl Med. 2013;11:191.

18. Du J, Cullen JJ, Buettner GR. Ascorbic acid: chemistry, biology and the treatment of cancer. Biochim Biophys Acta. 2012;1826(2):443-457.

19. Aditi A, Graham DY. Vitamin C, gastritis, and gastric disease: a historical review and update. Dig Dis Sci. 2012;57(10):2504-2515.

20. Sexton P, Black P, Metcalf $P$, et al. Influence of mediterranean diet on asthma symptoms, lung function, and systemic inflammation: a randomized controlled trial. J Asthma. 2013;50(1):75-81.

21. Jialal I, Singh U. Is vitamin C an antiinflammatory agent? Am J Clin Nutr. 2006;83(3):525-526.

22. World Health Organization (WHO) Department of Non-communicable Diseases. Global Physical Activity Questionnaire: Analysis Guide. Geneva: WHO; 2002. Available from: http://www.who.int/chp/steps/ resources/GPAQ_Analysis_Guide.pdf. Accessed May 26, 2015.

23. Block G, Jensen C, Dietrich M, Norkus E, Hudes M, Packer L. Plasma C-reactive protein concentrations in active and passive smokers: influence of antioxidant supplementation. J Am Coll Nutr. 2004;23(2): 141-147.

24. Centers for Disease Control and Prevention (CDC). Behavioral Risk Factor Surveillance System Survey Questionnaire. Atlanta, GA: US Department of Health and Human Services CDC; 2011.

25. WHO. Obesity: Preventing and Managing the Global Epidemic: Report of a WHO Consultation. WHO Technical Report Series 894. Geneva: WHO; 2000. Available from: http://www.who.int/nutrition/ publications/obesity/WHO_TRS_894/en/. Accessed May 26, 2015.
26. National Institute for Health and Clinical Excellence. Obesity: The Prevention, Identification, Assessment and Management of Overweight and Obesity in Adults and Children. London: National Institute for Health and Clinical Excellence; 2006.

27. Cárcamo JM, Bórquez-Ojeda O, Golde DW. Vitamin C inhibits granulocyte macrophage-colony-stimulating factors-induced signaling pathway. Blood. 2002;99(9):3205-3212.

28. Choi JS, Choi YJ, Park SH, Kang JS, Kang YH. Flavones mitigate tumor necrosis factor-alpha-induced adhesion molecule upregulation in cultured human endothelial cells: role of nuclear factor-kappa B. J Nutr. 2004;134(5):1013-1019.

29. Wu X, Schauss AG. Mitigation of inflammation with foods. $J$ Agric Food Chem. 2012;60(27):6703-6717.

30. Jang IS, Ko YH, Moon YS, Sohn SH. Effects of Vitamin C or E on the Pro-inflammatory Cytokines, Heat Shock Protein 70 and Antioxidant Status in Broiler Chicks under Summer Conditions. Asian-Australas J Anim Sci. 2014;27(5):749-756.

31. Peluso I, Villano D, Roberts S, et al. Consumption of mixed fruit-juice drink and vitamin $C$ reduces postprandial stress induced by a high fat meal in healthy overweight subjects. Curr Pharm Des. 2014;20(6): $1020-1024$.

32. Zhang KY, Li YH, Cheng XY, et al. Cross-over study of influence of oral vitamin $C$ supplementation on inflammatory status in maintenance hemodialysis patients. BMC Nephrol. 2013;14:252.

33. Block G, Jensen C, Dalvi T, et al. Vitamin C treatment reduces elevated C-reactive protein. Free Radic Biol Med. 2009;46(1):70-77.

34. Wannamethee SG, Bruckdorfer KR, Shaper AG, Papacosta O, Lennon L, Whincup PH. Plasma vitamin C, but not vitamin E, is associated with reduced risk of heart failure in older men. Circ Heart Fail. 2013;6(4):647-54.

35. Wannamethee SG, Lowe G, Rumley A, Bruckdorfer KR, Whincup PH. Associations of vitamin $\mathrm{C}$ status, fruit and vegetable intakes, and markers of inflammation and hemostasis. Am J Clin Nutr. 2006;83(3):567-574; quiz 726-727.

36. Aguiló A, Monjo M, Moreno C, Martinez P, Martínez S, Tauler P. Vitamin $\mathrm{C}$ supplementation does not influence plasma and blood mononuclear cell IL-6 and IL-10 levels after exercise. J Sports Sci. 2014;32(7): $1659-1669$.

37. Khajehnasiri F, Mortazavi SB, Allameh A, Akhondzadeh S. Effect of omega-3 and ascorbic acid on inflammation markers in depressed shift workers in Shahid Tondgoyan Oil Refinery, Iran: a randomized double-blind placebo-controlled study. J Clin Biochem Nutr. 2013; 53(1):36-40.

38. Afkhami-Ardekani M, Shojaoddiny-Ardekani A. Effect of vitamin C on blood glucose, serum lipids and serum insulin in type 2 diabetes patients. Indian J Med Res. 2006;126:471-474.

39. Sargeant LA, Wareham NJ, Bingham S, et al. Vitamin C and hyperglycemia in the European Prospective Investigation into Cancer - Norfolk (EPIC-Norfolk) study: a population-based study. Diabetes Care. 2000; 23(6):726-732.

40. Dakhale GN, Chaudhari HV, Shrivastava M. Supplementation of vitamin $\mathrm{C}$ reduces blood glucose and improves glycosylated hemoglobin in type 2 diabetes mellitus: a randomized, double-blind study. Adv Pharmacol Sci. 2011;2011:195271.
Drug Design, Development and Therapy

\section{Publish your work in this journal}

Drug Design, Development and Therapy is an international, peerreviewed open-access journal that spans the spectrum of drug design and development through to clinical applications. Clinical outcomes, patient safety, and programs for the development and effective, safe, and sustained use of medicines are a feature of the journal, which
Dovepress

has also been accepted for indexing on PubMed Central. The manuscript management system is completely online and includes a very quick and fair peer-review system, which is all easy to use. Visit http://www.dovepress.com/testimonials.php to read real quotes from published authors. 